\title{
OPERATIONAL RESEARCH: A MULTIDISCIPLINARY FIELD
}

\author{
René Victor Valqui Vidal \\ Informatics and Mathematical Modelling \\ Technical University of Denmark \\ 2800 Lyngby - Denmark \\ vvv@imm.dtu.dk \\ * Corresponding author / autor para quem as correspondências devem ser encaminhadas \\ Recebido em 11/2004; aceito em 07/2005 \\ Received November 2004; accepted July 2005
}

\begin{abstract}
This paper is focusing on the following question: What is Operational Research (OR)? We will show that there is not a single and simple answer. Epistemological assumptions and practical traditions define different types of OR. We have identified three: The technical or hard OR, the practical or soft OR, and the critical OR. Following a historical perspective we will present these three schools. Habermas' theory about the three cognitive interests will provide a framework to understand this development. Finally, some final remarks about the future of OR will be outlined.
\end{abstract}

Keywords: hard OR; soft OR; critical OR; creativity. 


\section{Introduction}

There is not a single and simple answer to the question: What is OR? Most operational researchers are confronted with two serious problems: lack of identity and legitimation of our discipline. Lack of identity is related to the specification of our abilities, our craft. Looking at OR journals or talking with participants of international OR conferences will not give a specific answer to our previously formulated question. Some OR people are good computer programmers. Others are good applied mathematicians, while others are good sociopsychologists. Some are good model builders; others are good model solvers. Some are good at identifying problems, others are good at solving problems and others are good at inventing problems. This identity problem, this alienation from Society, is also a problem for other professional disciplines. The legitimation problem is: How to explain to ordinary people the necessity of OR for Society? This problem is related to the first one - it is difficult to argue for legitimacy of something that it is very difficult to define.

Now-a-days, after a turbulent history, it is accepted in the OR community that there are various ways of researching, practising, learning and teaching OR. Three main "schools" have been identified: Hard OR, Soft OR and Critical OR. The main purpose of this paper is to present the main characteristics of these different modes of conceptualising and practising OR. Historical, epistemological, and sociological aspects will be enhanced in our discourse to give a holistic and historical view of OR.

In Section 2, the scene of a real-life OR project will be presented. The different types of organisations, actors, researchers, methods, etc. that usually are presented in such projects will be shortly defined.

Section 3 will be devoted to hard or technical OR. First, a characterisation will be given by specifying some epistemological stipulations. Secondly, the ideas behind two of the most used hard approaches, optimisation and simulation, will be shortly presented. Finally, the critique of hard OR will be outlined.

Soft or practical OR will be the theme of Section 4. In addition, the epistemological stipulations that characterises soft OR will be also presented. Moreover, a family of soft approaches known as problem structuring methods will be briefly discussed. Finally, the critique of soft OR will be also outlined.

The different movements to develop a critical OR will be subject of Section 5. A critical approach known as Critical Systems Heuristics will be also presented. Finally, the work of radical OR workers will be discussed giving emphasis to what is known as Community OR.

The aim of Section 6 is to view the development of OR through the lens of the sociological school known as Critical Theory; in particular the studies of Habermas on the three knowledge-constitutive interests: the technical interest in the control and manipulation of the physical world; the practical interest in communicating with and understanding other people; and the emancipatory interest in developing and freeing ourselves from false ideas, will be outlined.

Finally, the last section will present the new perspectives for OR in what concerns methodologies and future practices. This paper is an introduction to many multidisciplinary subjects, further studies can be carried out by consulting Ackoff (1999), Mingers (1992), Keys (1995), and Vidal (1994, 1995). 


\section{Decision-Making and OR: The Scene}

The point of departure in our discussions is the concept of an organisation. An organisation can be a family, a community, a corporation, or an institution. What characterises organisations is that they are purposeful and specially designed to achieve a task; that is organisations are teleological. Thus, an organisation in a community could be a centre designed to enforce the development of the region, while firms are organisations providing some products and profits, and institutions are organisations designed to provide some services. The evolution of organisations are conditioned by external and internal factors, and sometimes organisations are experiencing problematic situations or messes, that is complex situations where some purposeful action is demanded to achieve some goals and visions. Problematic situations are usually related to the introduction of new technology, the redesign of the organisation, the development of new strategies for the organisation, the formulation of new visions for the future, or problem solving in general. In such a situation, the organisation will usually appoint $a$ work group to deal with the problematic situation. The task of this group is to analyse the mess and answer the question: What is to be done? In other words, to propose action plans to be approved by the decision-makers of the organisation. In small organisations the decision-makers (managers) are usually part of or identical to the work group. Related to these persons we have the so-called stakeholders, those individuals outside or inside the organisation that can either affect or be affected by the actions plan. The decision-makers, the work group and the stakeholders are usually denominated as actors.

To deal with messes, it is recommendable for the work group to hire for example an operational researcher. The operational researcher will support the group in the problem solving process, he or she will secure that the problem solving process ends with an action plan to be approved by the decision-makers. Usually the OR worker will also provide some technical knowledge.

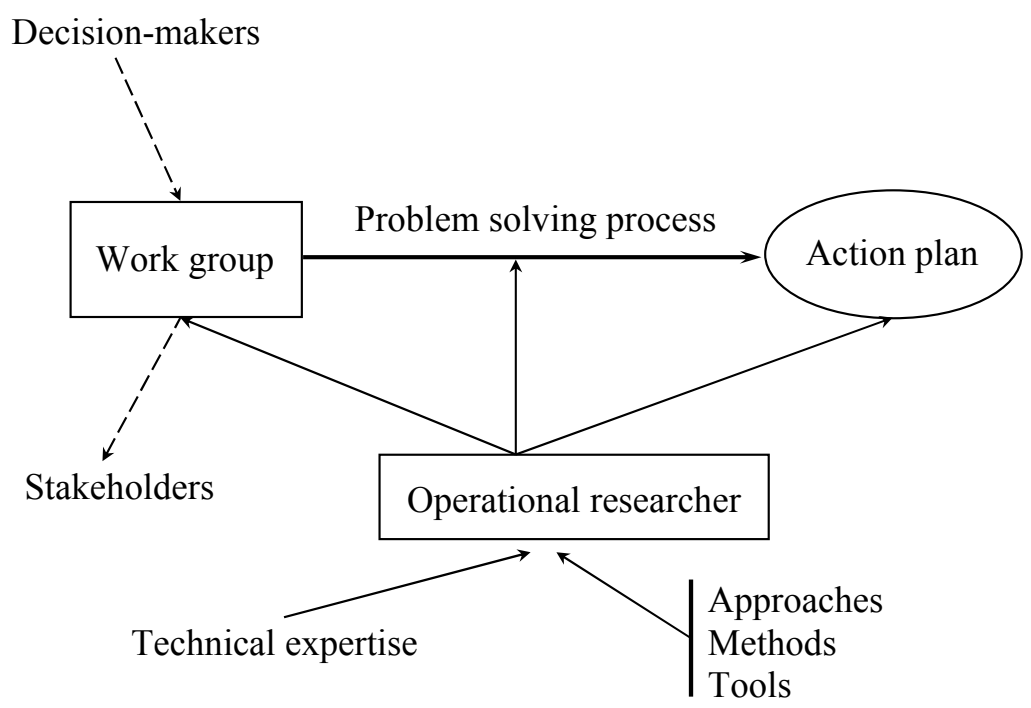

Figure 1 - OR supporting problem solving. 
To perform his job the operational researcher uses some methodologies (approaches, methods and tools) that he/she finds suitable for the given situation. The approaches could be quantitative (hard), qualitative (soft), participative (critical), innovative (creative) or a combination of them (multimethodology).

Figure 1 depicts the different elements of an OR project and their interconnections. The description of this social process is very abstract and idealised. Many concepts need to be further specified. This will be done in the following sections. Different types of methodologies and relations between the actors and the OR worker will mean different forms of OR practice.

In such general terms, OR can be conceptualised as a problem-, consulting-, and researchoriented discipline using a methodology to support a group work to deal with a problematic situation. Two essential characteristics of the OR approach are:

- Problem structuring of the mess; and

- Modelling as a tool for problem solving.

A third aspect in the characterisation of OR is related to the question: Whom are you working for? Who is the user or client? OR practice shows different alternatives, thus you can work for:

- Top management; the OR worker will be an adviser;

- All actors trying to achieve consensus; the OR worker will be a mediator; or

- Oppressed groups, the OR worker will be a facilitator trying to empower them.

\section{Hard or Technical OR}

The origin of traditional OR, also called hard or technical OR, is dated back to the Second World War. Both in England and the USA some scientists were dealing with planning and operational problems in action.

Traditionally, hard or technical OR is characterised by the following stipulations:

- Problem structuring using the principles of Machine Age thinking;

- Modelling using the principles of Natural Sciences (objectivisation and empiricism); and

- Working for a highly hierarchical organisation in close contact with top management, i.e. the operational researcher is an expert and adviser.

In hard OR the problem in study will be objectivised following the principles of natural sciences, it will be broken into parts (decomposition) and analytically studied using experimental data, measurement, quantification and mathematical modelling. Objectivisation means a total focus on quantitative and measurable variables, disregarding the subjective knowledge of the actors. Ackoff (1974) has characterised this approach as Machine Age thinking, i.e. as been analytical and based on the principles of reductionism and mechanicism.

Reductionism is the idea that all objects and events, their properties, and our experience and knowledge of them are made up of ultimate elements, indivisible parts. The role of Science is the search of these elements. Physics is considered as the basic experiential Science and Mathematics the tool for reasoning in a consistent way. Analytical thinking is a complement 
to reductionism. It is the mental process by which to understand anything is broken down into its parts. Explanation of the behaviour and properties of totalities were obtained from explanations of the behaviour and properties of their parts.

The analytical approach is also central to problem solving. Problems are reduced in size by analysis to a set of simpler problems, these are then solved and their solutions are assembled into a solution to the total problem. Following reductionism, all interactions between objects, events and properties are reduced by analysis to fundamental relationship, cause-effect. Therefore, the physical sciences are believed to be all that is required to explain life, such a view is called mechanism. Ackoff (1974) writes:

"Carried to its limit reductionistic causal thinking yields a conception of the universe as a machine. It was believed to be like a hermetically sealed clock, an environment-free selfcontained mechanism whose behaviour was completely determined by its own structure and the causal laws that applied to it."

This technocratic attitude is always present in traditional OR. Organisations are considered as large and complex machines, the job of the operational researcher is to understand and describe the functioning of them by discovering laws and building up mathematical models. This usually means an overemphasis of the technical and economical systems of an organisation, upon the social, human and political systems of the same organisations.

Traditional OR has always been at the service of those who have power and money. Studying real-life applications of traditional OR it is possible to see the servility, conformity, conventionality, and fixed ways of judging of operational researchers. They lack flexibility, their attitudes are very restricted and they are excessively loyal to present systems. This is partly a consequence of an OR education seeking only towards objectivisation and technical competence and not ethical and social responsibility. Consequently, hard OR workers are usually consciously or unconsciously politically conservative.

\subsection{Optimisation and simulation approaches (Pidd, 1966)}

In hard OR, the first step in problem solving is the construction of a mathematical model that objectively and quantitatively represents the problem to be solved. This model is composed of a criterion or utility function, usually costs, to be minimised subject to a set of constraints. Constraints can represent limitations in resources, economical demands or technical alternatives. Anyway, the mathematical model is an approximation based sometimes in some assumptions that are difficult to validate, for instance the assumption of quantification and linearity. In addition, the model demands the availability of some parameters that are difficult to estimate.

Linear Programming is the mathematical optimisation model most used and misused in OR practice. In this model the criteria and all constraints are linear. Effective and reliable software are available to solve large-scale problems. The main difficulty in real-life applications is to collect the huge amount of reliable quantitative data needed for large-scale problems.

In general, to obtain optimal solutions to non-linear and combinatorial optimisation models is not an easy task. A great deal of the OR researchers' work deals with the mathematical analysis of some standard and simplified optimisation models and the development of computerised software to find solutions in an effective way. Producing effectively optimal solutions to models that badly represent reality is not always a useful strategy in practice. 
Therefore, to solve realistic optimisation models in real life it is usually sufficient to find approximate solutions in an effective way using heuristic approaches. Simulation using a computer is one of the most usable approaches for getting satisfactory solutions. Moreover, simulation permits the experimentation with the model to evaluate the consequences of different alternatives. Effective and reliable simulation software is also available.

Technical OR has shown its strength when dealing with tactical well-defined problems such as: Production planning, investment planning, project planning, location of plants and terminals, design of distribution systems, transport planning, among others. Implementation of such models is secured by having close contact with top management. Implementation is not an easy task when the other actors do not want to co-operate.

\subsection{The critique of hard OR}

After the Second World War, OR was transferred to both the public and the industrial sector in the UK and the USA. During the 50's and 60's, OR expanded also to other industrialised countries. By the end of the 60's, OR was established as an academic discipline in most of the industrialised countries, and it was practised by consulting firms, company-groups and research associations.

The 70's can be considered as the decade of crisis and the birth of an alternative OR, the so-called soft (contrary to hard) or practical OR. Rosenhead (1989) gives the following picture: "Major turmoil erupted in the world's largest OR societies over plans to "professionalise" the British operational research community (1972-1973) and over the Operational Research Society of America's attempts to establish a code of conduct and discipline offenders (1971-1972). Dispute of non-technical nature flared in the normally sedate columns of respected journals... Ackoff engaged in an extended exchange with radical critics... he himself launched a scathing attack on mainstream OR practice... which evoked support for his diagnosis but not for his proposed remedy".

Much of these debates have sprung from US experiences. Thus for instance, the ORSA code was the response of the academy to a crisis situation where two renowned consulting firms gave a complete different advice, one working for the White House and the other for the Congress, on decisions related to the development of a large-scale military project. The experience was that the methods, which had seemed to work well on more limited problems, fell apart when given a chance to show their paces on more ambitious projects. The "moonghetto metaphor", formulated in Nelson (1974) as the assumption that methods capable of getting a person on to the moon could with advantage be used on such lesser matters as solving the problems of inner city ghettos, proved to be a delusion.

Let us see more explicitly some of the criticisms of hard OR as they have been formulated in the literature:

- There are criticisms concerned with the demand for quantification and optimisation. When working with complex systems, the design of a quantitative model is inevitably a highly selective process and necessarily it will reflect the limitations and biases of its creators. Instead of recognising this fact and making explicit the hidden assumptions, there is a tendency to treat the model readily as synonymous with the reality. Then the mathematical model becomes the focus of attention, and experimentation, manipulation and generation of optimal solutions is the main task of 
the OR worker. This causes that most attention is paid to the model and its solution than the real-life problem to be solved, this tendency is usually called "model escapism". Teaching and research activities at universities are usually dealing with mathematical models, as well as papers published in OR and related journals. It is this manipulation of models for their own sake that has led to OR being characterised as "mathematical masturbation". Another consequence of the demand of mathematical modelling is the tendency to disregard those factors in reality that are not amenable to quantification or to distort them in the quest for quantification. Lastly, let us mention a critic point related to the implemented model, usually the users will not be able to understand the contents of the model, the results will be used as an act of faith, and in addition the user is not able to make changes in the model. In some situations the model will be given an important role in the problem solving process, it will be an authority, a computerised expert that is not able to explain in common language the way how the so-called "optimal solution" was found, this tendency is denominated "model fetichism".

- Another kind of criticism is related to the failure of OR to pay proper attention to the especial characteristics of the human beings in the organisations, which they sometimes aspire to deal with. People, when included, are treated as components of a big machine that have to be adapted so that the whole system operates optimally. Here it is argued for another conceptualisation of man, possessing understanding, having experience and his own personal knowledge and objective. This deterministic perspective in traditional OR thinking, which places the system before human beings, disregards the ability of man to intervene in their own destiny. Ackoff (1974) goes further and in this connection talks about the problem of humanising organisations: "Solution of this problem in whole-oriented organizations requires developing relevant incentives and ways of providing individuals with more meaningful participation in their organisations. Such participation implies giving individuals a role in making decisions that affect them directly and rewarding them appropriately for improved performance and increased responsibility. There is extensive evidence that such participation produces increased satisfaction and improves organizational performance."

- Finally, there are criticisms that point out the limitations of traditional OR in real-life problem solving. OR demands that objectives should be clearly defined from the very beginning of the problem solving process. This is suitable for engineering-type of problems where goals are easy to specify and attention can be concentrated on means. However, in many situations of strategic art the very definition of objectives will be the main problem. Technical OR is suitable for that class of problems for which there is a desired state, $\mathrm{D}$, and a present state, $\mathrm{P}$, and alternatives ways of getting $\mathrm{P}$ to $\mathrm{D}$. "Problem solving", according to this view, consists of defining D and P and selecting the best means of reducing the difference between them. In other words, technical OR consists of well-structured thinking related to means-determination in well-structured problems. The kind of problems adequate to the problem solving process of hard OR have been denominated as: well-structured, tactical, tame, or technical problems. Those problems where traditional OR seem inappropriate have been denominated as: ill-structured, strategic, wicked, or practical problems. In these last type of problematic situations or messes there will exist some general statement of a purpose to be achieved. The output of a study must propose some arguments in favour of accepting a way to structure the mess that leads to a corresponding means of solution. 
The first two criticisms are related to the epistemological stipulations of hard OR while the last criticism is related to the practice of hard OR, focusing primarily in problem solving rather than the structuring of messes.

\section{Soft or practical OR}

Soft OR emerged during the 70's as a result of dissatisfaction with the development and limitations of traditional OR. A number of approaches were developed which in various manners countered the traditional assumptions of technical OR and took seriously the distinctive nature of human beings in decision-making processes in organisations.

Soft or practical OR can be characterised by the following stipulations:

- Problem structuring using the principles of Systems Age thinking;

- Qualitative modelling using the principles of Hermeneutic-Phenomenology (interpretation, conceptual models, and intersubjectism); and

- Working for organisations where all the actors participate actively in the problem structuring and problem solving process, i.e. the operational researcher is a facilitator.

In Soft OR the attitude towards science is one, which takes as its prime datum not the world external to the observers of it, but the observer's mental processes. The phenomena or situation in study will be modelled based on the actors' subjective conceptualisation of the situation and using such techniques as interviews, dialogue, discussions, work-shops, conferences, etc. Thus, practical OR offers a human-culturalist approach to compare and contrast with the technical-naturalistic approach of traditional OR. In Soft OR, man is conceptualised as constantly creating and recreating the social world in interaction with others. The actors are negotiating their interpretations of reality itself. This scientific tradition is the predominant one in the Human and Social Sciences. Hermeneutics means the science of interpretation, while phenomenology is a philosophical position characterised by a readiness to concede primacy to the mental processes of observers rather to the external world.

In addition, in most soft OR approaches some of the principles of systems thinking will be used to structure the mess and to construct a conceptual model of the situation on hand. This stipulation has been called by Ackoff (1974): Systems Age thinking. Here the doctrines of reductionism and mechanism, and the analytical thinking of the machine age have been replaced by the doctrines of expansionism and teleology, and a new holistic systems thinking. Let us elaborate about these ideas.

Viewed structurally, a system is a divisible whole; but viewed functionally it is an indivisible whole in the sense that some of its essential properties are lost when taken apart. In the Systems Age thinking things are looked as part of larger wholes rather as wholes to be decomposed. This is the doctrine of expansionism. Expansionism brings with it the holistic mode of thought, where something to be explained is viewed as part of a larger system and is explained in terms of its role in the larger system. The holistic way of though, when applied to problematic situations, is called the systems approach. This new way of thinking is necessarily interdisciplinary, that is a variety of relevant disciplines work cooperatively on the problematic situation as a whole. 
Another central doctrine in the Systems Age is the doctrine of teleology - the study of a goalseeking and purposeful behaviour. In mechanistic thinking behaviour is explained by identifying what caused it, never by its effect. In teleological thinking behaviour can be explained either by what produced it or by what it produces or is intented to produce.

Because the Systems Age is teleologically oriented, it is concerned with systems that are purposeful; that is, with systems that can display choice of both means and ends. In addition, in the Systems Age man is more concerned with those purposeful systems whose parts are also purposeful, with groups - in particular, with those groups whose parts perform different functions.

Similarly to mechanistic thinking, the idea of systems thinking has been originated in the natural and engineering sciences, and thereafter transferred to the study of social systems. Systems thinking is an abstraction of the experiences obtained during the development and utilisation of automation technology. Another source of inspiration has been the study of organisms in biology.

\subsection{Problem structuring methods (Rosenhead, 1989)}

A set of soft OR approaches are denominated as Problem Structuring Methods, or PSMs for short. These are model-based approaches for contributing constructively and appropriately to the resolution of problematic situations or wicked problems. Some of the characteristics of these methods are:

- There are based on systems thinking.

- The models constructed are primarily qualitative.

- When needed they take account of several criteria without trade-offs for optimisation.

- The information included is an integration of hard and soft data with subjective knowledge.

- The work group and other actors will be facilitated by the OR worker through a problem solving process.

- They are simple and transparent, aimed at clarifying the terms of conflicts.

The three main approaches in the family of PSMs are: SCA (Strategic Choice Approach), SODA (Strategic Options Development and Analysis) and SSM (Soft Systems Methodology). The creators of these approaches have their background in traditional OR and systems engineering. All of them provide a problem structuring facility. Each deploys a repertoire of methods, any one of which may (or may not) be applied at some point in the course of a study. All of them are quite eclectic in their willingness to take other approaches under wings.

SCA supports decisions to be taken by a group of decision-makers providing different techniques to outline problem areas, focus, uncertainties, and portfolio schemes. The methodology acknowledges uncertainties in decisions and uses different techniques to conceptualise and deal with them. It takes account of several criteria, seeking consensus through discussions in a workshop. Analysis of decision trees are utilised to eliminate undesirable combination of alternatives. SCA emphasises on the choice between candidate decisions, this method is more conventionally in an OR sense. Preferences, values, rankings, and the like do, of course, feature - but as means of comparing or excluding various decisions options rather than as subjects of equivalent status. 
SODA takes into consideration the individual members of the groups and conceptualises different problem views constructing individual cognitive maps that late can be used as basis for a workshop for negotiating a consensus. SODA emphasises the problem solving process but, despite its OR pedigree, employs a technique which is not predominantly decision focused. Cognitive mapping centres as much on identifying organisational goals as it does on decision options.

SSM combines the principles from systems thinking with more individual worldviews. It recognises that individuals have different problems perceptions and conceptualise these using a verbal modelling procedure. Consensus will be achieved by the elaboration of these conceptual models. SSM emerges from the somewhat different background of the systems approach, and indeed system design, the concern is more with how systems could work better, than with what decisions to take.

There are two main problems while using these PSMs. First, although the creators of these approaches argue that they are transparent and easy to use, practice shows that the use of them in real life demands a highly qualified facilitator with a lot of experience using these approaches. Secondly, workshops are essential elements in the problem solving process for the practical application of SCA, SODA, and SMM, but these workshops will be steered by the methods, this is not always desirable specially in situations where the group wants to work more creatively than rational. Vidal (2004a) has edited a special issue of EJOR that focus on real life applications of soft OR.

\subsection{The critique of soft $\mathrm{OR}$}

Practical OR opens up a new perspective on the way systems thinking can be used in the problem solving processes. The different soft approaches are concerned to cope with messes at the strategical level. There is here an epistemological break, a change from empiricism to hermeneutics. In different ways soft approaches move away from a focus in mathematical modelling and manipulating a single objective reality towards exploring and expressing individuals' subjective meanings in order to achieve understanding and consensus.

Let us see more specifically some of the main criticisms raised to practical OR as they have been formulated in the literature:

- Soft OR is criticised for its "subjectivism" and for its consequent failure to come to terms with structural features of social reality. People create the social world, but it is not necessarily done in full awareness of what they are doing. People who have conflicting aims and intentions and who bring different resources to bear when the social construction is taken place create the social reality. It follows that the social world escapes the understanding and control of any one person or group of people. It takes on the form of a highly complex and structured external reality that exercises constraint on the individuals who make it up. Soft OR approaches are essentially regulative - that is unable to bring about radical change. This is partly due to its inherent subjectivism. In focusing on actors' ideas and perceptions they are unable to theorise the cause and preconditions of such World View, or the constraints of power and interest. They lack a social theory. Any change they bring about will therefore be limited by the distorted nature of the prevailing situation. This critique can be related to a meta-theoretical critique of hermeneutics, as formulated by Habermas (1976). The main problem with hermeneutics is: its naturalisation of tradition, authority, and 
language, thereby implying distortion-free communication situations. In other words the critique of hermeneutics points to its exclusive concern with the selfunderstanding of social agents. By excluding any consideration of the possibility of self-misunderstanding, ideology, and domination, it legitimates the status quo and precludes the possibility of critical self-reflection.

- One of the main hidden assumptions in practical OR is the idea of consensus worldview. This is the idea that conflict situations can always be solved by negotiation and discussion. The alternative position, that there are some conflicts in organisations and Society that are related to immanent contradictions of the system, and that will permanently be present and that are usually settle by the use of power, is not existing in the epistemology of Soft OR.

- It is assumed, in soft OR, that the possibility of participation is always present and it is seen as the cure of many problems in organisations. Participation is an essential feature of Soft OR, epistemologically because it provides the justification for the objectivity (intersubjectivity) of the results and practically because it generates creativity and ensures implementation. Soft OR depends on all the actors being ready for participation, but will the powerful be willing to forgo their dominant position and submit their privileges to an unpredictable soft approach? Soft OR assumes a democratic problem solving process with equal participation of the actors in a Society where organisations are not characterised by being democratic in their decisionmaking process. We cannot realistically expect that less privileged stakeholders will be able to participate equally in the problem solving process because they will not be carried out within their premises. The less privileged may additionally feel threatened by the powerful, and limit their demands to what is "realistic". The oppressed groups may even find themselves under the sway of a dominant ideology, through the mists of which they fail altogether to recognise their own true interest. Or, they might have a lack of interest or apathy for participation at any level of the organisation. Any discussion or debate among stakeholders can only, therefore, be exceptionally constrained. In general, therefore, it seems that the results obtained by practical OR will favour the powerful.

- Another unhidden assumption in soft OR is that the scope of their projects do not challenge their clients or sponsors' fundamental interests, the OR worker is usually working with managers sharing similar interests. These clients usually have the power to impose agreement on any other groups involved in the problem solving process. Working for powerful clients will restrict the emergence of alternative, radical worldviews in soft OR and lead only to reformist recommendations for change.

These criticisms are based on the epistemological assumptions of soft OR and on the social practices of the soft OR workers. These should be related to the similar critique that can be raised to hard OR that also offers succour to the status quo and to the already powerful. This is explicitly formulated in hard OR, while in soft OR it is unhidden and only discovered by analysing the social praxis of their work. This is why from a political point of view, soft OR people are considered as being consciously or unconsciously reformists/social democrats. Hard and soft OR encourages depolitisation and scientisation. Thus conflict is hidden. Moreover, both OR approaches are contributing to the further technocratisation of Society by providing expertises that are either able to manipulate with mathematical models or that are able to manipulate directly with individuals. It is in this sense that OR, both hard and soft, can be considered as an ideology. It flourishes because of the service it renders to the elites in Society, presenting, analysing and supporting a view of reality that justifies the privileged. 


\section{Critical OR}

Several researchers have attempted to realise the idea of developing a critical theory in the particular realm of OR, Management Science, System Sciences, and related sister disciplines. The most distinctive characteristic of these disciplines is that they are essentially orientated towards taking action within specific problematic situations. This leads to the demand for practical methodologies and techniques, which can be used by and on behalf of the actors within systems of purposeful activity facing problematic situations.

The work so far carried out within what we can call critical OR can be broadly categorised under three themes. First, providing criticisms of technical and practical OR. Secondly, developing specific critical approaches and methodologies. And thirdly, practising a radical OR based on a political conceptualisation of participation, empowerment and emancipation.

\subsection{Criticisms of technical and practical OR}

These critiques have been outlined in previous sections of this paper. It is important to emphasise that two central criticisms are applicable to both hard and soft OR:

- They are both regulative, i.e. in practice they work to sustain rather than challenge the status quo. Since they cannot admit external structures and constraints they cannot recognise nor challenge inequalities of power, resources and knowledge within a particular setting. Changes that may be desirable generally have to be subordinated to the feasibility of the existing power structure, and where new ideas are initiated, barriers to change cannot be dealt with.

- Implicit within them are, largely unarticulated, assumptions about power and basic ideology. They share an essentially functionalistic view of power, i.e. that power is a societal or organisational capacity for securing order and consensus - power is equated with authority. In terms of ideology, they are based on liberal ideas of the free-individual, free-market competition and democracy.

\subsection{Critical methodologies}

One major contribution to critical approaches has been Ulrich's Critical Systems Heuristics developing an "emancipatory" systems research for social planning. Ulrich is focusing on the problems of participation.

Ulrich (1983) criticises the currently use of systems ideas in soft OR, which is dominated by limiting mechanistic and organismic analogies and where the systems ideas are only used with the technical purpose to help to decide how to do things. His purpose is to develop methodology to help to decide what ought to be done. He proposes critical systems heuristics, using each of these three concepts in the sense given by Kant:

- Critical: Reflect upon the presuppositions behind the search for knowledge. Make transparent to yourself and the actors the normative contents of propositions. Submit all propositions to critical assessments and discussions.

- Systems: Refer to the totality of the relevant (metaphysical, ethical, political, and ideological) aspects upon which theoretical and practical judgements depend. It is by reference to the whole systems concepts entering into partial presuppositions that critique becomes possible. 
- Heuristics: Refers to a process of uncovering objectivist deceptions and helping the actors to unfold problems trough critical reflection. It is a method by which presuppositions and their inevitable partiality can be kept constantly under review.

Kant hoped to justify the kind of knowledge we have about the world. He was especially concerned about what he called synthetic a priori concepts, i.e. concepts that are deeply implicated in the production of knowledge but are little understood and difficult to justify. Ulrich applies Kant's ideas to planning and systems design. Some presuppositions, in the form of boundary judgements (relevant factors), inevitably enter into any social systems design. Thus boundary judgements provide an access point to the normative implications of systems design. The task is to find ways of interrogating systems designs to discover the boundary judgement being made. Ulrich formulates twelve critically heuristic questions (see Table 1) around a fundamental distinction between those involved in any planning decision and those affected.

Table 1 - The twelve critically heuristic questions.

1. Who is the actual client of the systems design?

2. What is the actual purpose of the systems design?

3. What is built-in measure of success?

4. Who is actually the decision-maker?

5. What conditions of successful planning and implementation of the system are really controlled by the decision-maker?

6. What conditions are not controlled by the decision-maker (i.e. are in the environment)?

7. Who is actually involved as planner?

8. Who is involved as expert, and of what kind is the expertise?

9. Where do the involved seek the guarantee that their planning will be successful?

10. Who among the involved witnesses represents the concerns of the affected without being involved?

11. Are the affected given an opportunity to emancipate themselves from the experts and to take their fate into their own hands?

12. What worldview is actually underlying the design of the system? Is the view of (some of) the involved or of (some of) the affected?

Ulrich has also shown how, making use of these questions; particular social systems design can be validated and accepted for implementation. Here it is required some form of participative debate to provide the final justification for practical knowledge. Affected citizens can employ boundary judgements against planners and formulate alternative boundary judgements. Then the burden of proof is shift to the planners. It should be clear that only agreement among all affected citizens can finally lead to conclusions about what ought to be done. The main idea is to bring the systems rationality of planners directly in contact with the social rationality of those who have to live in and experience the social systems designs.

No doubt, compared with soft approaches; Critical Systems Heuristics give a significant step forward for generating critical awareness in social planning. The emancipatory potential of 
the approach can hardly be in doubt. The main limitation of this approach is its lack of social and political awareness. Ulrich's approach allows us to reflect upon the ideas that enter into any social systems design, but it does not help us to reflect upon the socio-economic and political conditions that give rise to those ideas and that led to certain ideas holding sway. The approach is idealistic, utopian and political naïve. It disregards how the political system works in practice. Why should the involved bother to take account of the views and interests of those affected but not involved? The discussion of the relationship between power and rationally is of central importance to discuss any theme related to the design of democratic decision-making processes.

\subsection{Radical OR}

The main purpose of radical OR is to participate in the struggle of and to contribute to the emancipation and empowerment of oppressed groups. This is a form of critical OR that has an explicit political purpose. Three kinds of activities can be identified:

- Demystifying and unveiling the nature and purpose as well as the consequences of OR projects having great impact in oppressed groups. For instance, technical OR studies of industrial branches will usually propose the construction and location of new large plants and terminals to achieve the main criterion of minimising costs. These studies usually disregard the social consequences for the workers, and employees that will loose their jobs. Or, for those who have to move to other towns to keep their jobs. Historically, this economic centralisation has had devastating consequences for those communities missing job opportunities.

- In the public sector, radical OR workers can help to expose and demolish official plans and to generate counter-plans, based explicitly on the interest of oppressed groups. Usually, operational researchers will join other groups as radical engineers, economists, sociologists, computer scientists, etc., and co-operate with local groups, trade unions and NGO's.

- To support oppressed groups to cope with the many problematic situations they are facing in their endeavour to survive and to empower them in their ability to deal with messes. A great deal of experience in this kind of work is found in the so-called Third World.

In 1986, the council of the British OR Society launched an initiative to found a centre for Community OR. Three main views of the motivation for Community OR has been articulate as follows:

- Clients should be organisations with particular characteristics: those with little resources, those participatively organised and those that represent people's interests.

- Community OR can enhance traditional OR by providing a fertile ground of unusual problems and new types of clients.

- OR should be socially committed, aiming to improve Society.

The council invited submissions from institutions interested in housing a Unit. The level of the response can gauge the timeliness of the initiative. Some eleven institutions entered submissions and most were able to support them with practical demonstration of community OR projects which were in progress or which had been completed. The submission finally selected involved the Northern College of Residential Adult education. 
The Northern College was newer to OR, and largely unknown to OR practitioners. As a residential adult education college, it provides continuing education for mature students who enter the College with a minimum of prerequisite formal educational qualification. Its distinctive feature, and its particular suitability as the location for the Community OR Unit lies in its Short Course Programme. The College specialises in group development. Students enter the College as a management committee, a steering committee, or just as a group of activists within their local tenants association, unemployment centre, women's group, black group, community health group, history group, writers group, etc. Whilst in the College, they will pursue a course of study designed specifically around their particular group needs, moulded by them together with one of the short course organisers working in the field. It is this aspect of the College's work that has provided unique opportunities for community OR. Whether entering the College in response to a specifically identified problem situation or merely as a part of a more routine review of their operation and effectiveness, community groups find themselves grappling with messes bearing similar general characteristics to those found in OR's more conventional setting in industry, business, commerce, or the public sector.

As well as having much to offer each other in terms of methods, OR and adult education have much to exchange in terms of practice. Adult education has long been familiar with the application of the pedagogic theoretical principles of for instance Paulo Freire (1972). These have been developed, as a research methodology, into the approach known as Participatory Research. This approach is itself a derivative of the sociology school known as Action Research. Freire deployed two significant theoretical constructs, which the Unit is using in its work: the concept of "conscientisation" and the method of "thematic investigation". The first is described as learning to perceive social, political and economic contradictions and to take action against the oppressive elements of reality. In this process, thematic investigation involves participation in an ever-deeping analysis of concepts and experiences common to their reality in order to question common assumptions and achieve a better understanding of that reality. In participatory research, the researcher's standpoints shift away from that of a detached observer and takes up the concerns and issues of the people being worked with. Participatory research is not a recipe for social change, but a democratic approach to investigation and learning to be taking up by individuals, groups and movements as a tool aimed to social change. This means that the Community OR Unit has adopted a methodological eclecticism concerned with the production of social change. The Unit would share the belief that the fundamental role of the researcher is a co-producer of learning.

Community OR in the UK is promoted and practised by a broad spectrum of OR workers, from hard and soft OR workers that are interested in methods and that latter will use the same approaches to serve those who have power, to humanitarian OR workers that want to contribute to a more human Society, and to radical OR workers that are following some specific political strategy.

A number of particular problems and limitations in undertaking community OR has been identified. Let us shortly see some of them:

- There is the difficulty of the actual presentation of what OR is or can offer. A difficult enough task in conventional circumstances as we have seen in earlier sections. Some practitioners have suggested that the words operational research may never enter into the engagement. This attitude reflects the view that groups will be antagonistic to the use of jargon. 
- There are a number of factors concerned with the on-going relationship between the group and the analyst such as maintaining credibility, knowing the area, and disengaging from the project.

- Community work demands some qualifications that usually are disregarded in OR education, this for instance the task of being a facilitator of problem solving groups.

Another issue is whether it is possible to define a boundary between a veritable OR contribution and just community work? And a boundary between Community OR and community work practised by other disciplines as for instance the sociological school called Action Research?

\section{Habermas' Critical Theory}

According to Habermas (1974), man possesses two fundamental cognitive interests that direct his attempts to acquire knowledge: a technical and a practical. These two interests are quasi-transcendal, i.e. they necessarily derive from the sociocultural form of life of mankind, which is dependent on work and interaction. The importance of work for mankind directs knowledge toward a technical interest in the prediction and control of natural and social systems. Interaction requires human beings to secure and expand the possibilities for intersubjective understanding among those involved in social systems. The importance of interaction leads the human species to have practical interest in the progress of mutual understanding.

The need for physical survival and manipulation of the environmental has led to the development of technical knowledge, the purpose of which is prediction and control. This has been supplied by natural (or empirical-analytical) science, which is fundamentally instrumental. They aim to produce theoretical statements about the covariance of observable events from which can be derived laws like hypotheses or theorems.

In humans, the development of language led to the possibility of communication and cooperative coordination of action. In this domain of practical activity, the fundamental need is for understanding - making sense of what others mean - and through discussion and argument, reaching agreement and consensus. This provides a foundation for the interpretative or cultural sciences such as hermeneutics. These sciences seek to access meaning and to gain an understanding of the creation of the intersubjective life world. They aim at maintaining and improving mutual understanding among human beings. These are the sciences focusing on the communication among individuals.

In an ideal world, these two knowledge domains would be sufficient. However, Habermas argues that the socio-political environment in which they have developed has distorted both of them. The instrumental rationality of natural sciences has been illegitimately applied to the social realm, and our language and communication are constantly undermined by the power structures of society and the lack of free and open discussion. There is thus a need for a third type of knowledge - critical science and philosophy - that aims to reveal these illusions and distortions. Human beings have an emancipatory interest in freeing themselves from constraints imposed by power relations and in learning, through a process of genuine participatory democracy, to control their own destinies and to self-development and freedom from ideology and false belief. Tied to the emancipatory interest are the critical sciences. These recognise the limitations of the other types of knowledge (and the dangers when there 
are inappropriately applied) and attempt to synthesize and go beyond them in order to provide knowledge that will enable people to reflect on their situations and liberate themselves from domination by forces that they are involved in creating but that they cannot understand or control.

These three knowledge-constitutive interests and their characteristics are summarised in Table 2 .

Table 2 - The three knowledge-constitutive interests (Mingers, 1992).

\begin{tabular}{|l|l|l|l|}
\hline Types of Science & Cognitive Interest & Social Domain & Purpose \\
\hline $\begin{array}{l}\text { Natural Science } \\
\text { (empirical-analytical) }\end{array}$ & Technical & Work & Prediction/control \\
\hline Cultural Sciences & Practical & Language/culture & Understanding/consensus \\
\hline Critical Sciences & Emancipatory & Power/authority & Enlightenment \\
\hline
\end{tabular}

Critical Theory or Critical Hermeneutics is an attempt to mediate the objectivity of historical processes with the motives of those acting within it, the aim being the freeing of emancipatory potential. The approach seeks to remove barriers to understanding that may be operative without the individuals or groups concerned being aware of them. Habermas (1972) has criticised the doctrine of value freedom. Empirical-analytical sciences are constituted by, and hence presuppose, the technical interest which aims at the instrumental control of natural and social processes and which therefore cannot be considered ethically neutral. More generally, objectivism, by implying that empirical knowledge is objective, neutral and rational, misrepresents and mystifies socially created, historically specific phenomena as natural, eternal, and unalterable. These contribute to a false conception of a false reality and therefore working to conceal, if not reinforce, the dominative, repressive and exploitative nature of Society.

It is from this terminology on knowledge-constitutive interest that comes the terms technical, practical and critical OR to characterise the different forms of practising OR. The previous sections have shown how the development of OR can be seen as successively embodying these three views. Section 3 traced the early days of OR, when it developed as technical knowledge concerned with the manipulation and control of an objective world, finding efficient ways of reaching pre-defined goals. Section 4 presented the development of soft OR in which attention changed to the subjective world of individuals' beliefs and perceptions, mirroring the practical domain of hermeneutics and phenomenology. Finally, Section 5 focused on the development of critical OR.

\section{New Perspectives}

What is the future of OR? During OR's short history many radical changes have been identified. These have been outlined in the last sections. At the present hard, soft and critical $\mathrm{OR}$ are all alive and still going strong. These radical or paradigmatic changes are related to theory, practice, and the relationship between theory and practice. In this section four new research areas will be outlined. They will be the focus of many OR researchers and practitioners in the near future. 


\subsection{Multimethodology}

This area is focusing on the possibility of combining together different methods, or parts thereof, within a particular social intervention. Different types of methods focus on particular aspects of a problematic situation, therefore employing more than one method in combination will help to tackle the different aspects of a situation. In these sense, multimethodology just means employing more than one method in dealing with real life problems.

There are at least three reasons for using a multimethodological approach:

- Real life problematic situations are always multidimensional; there will be material, economic, social, political and individual aspects. Different methods tend to focus on different aspects of the situation and therefore multimethodology is needed to deal effectively with the complexity of the real world.

- A social intervention is not a single, here-and-now event but it is usually a process that typically is carried out through a number of stages, and these stages pose different tasks and problems. However methods tend to be more useful in relation to some stages than others, so the idea of combining them is appealing to achieve better results.

- Combining different methods even where they actually perform similar tasks (such as different mapping techniques) can usually generate new insights and provide more confidence in the results.

A suitable multimethodological approach to deal with a real life problematic situation has to be designed. This interaction between the field of Design and OR seems to be of great interest for future research.

Mingers and Gill (1997) have edited the first collection of papers about the area of multimethodology. There is a need for more practical applications to show the applicability of different forms of multimethodological approaches.

\subsection{Participative problem solving}

The development of Soft OR has given a central focus to the relationship between the actors and the OR worker during the problem solving process. Under such conditions the concept of participation is rather central when there is the need to combine practical and theoretical knowledge. The practical knowledge is coming from the experience and know-how of the actors. The theoretical knowledge is coming from the methodological know-how and experience of the OR worker.

The area of participation and problem solving is quite similar to the sociological school known as PAR (Participatory Action Research). In PAR some of the people in the organisation or community under consideration actively work with the professional social researcher throughout the research process from the initial design, to the final presentation of results and discussion of their action implications. PAR thus contrasts sharply with the conventional model of pure research, in which members of organisations and communities are treated as passive subjects, with some of them participating only to the extent of authorising the project, being its subjects, and receiving the results (Whyte, 1991).

OR has a lot to learn from PAR. Especially in the idea that Science is not achieved by distancing oneself from the world; as generations of scientists know, the greatest conceptual 
and methodological challenges come from engagement with the real world. A first step in this direction has been taken by Taket and White (2000). They have developed a framework, denominated PANDA (Participatory Appraisal of Needs and Development Action), that can be used to plan and implement group working and group decision making in a multiagency setting. PANDA represents one particular way of designing a multimethodological approach.

The use of participative approaches in practice demands the focusing on the following aspects of the problem solving process:

- Groups developing shared ideas and meanings.

- Issues are dealt primarily qualitatively.

- Focusing in learning processes in the group work.

- Debate and dialogue are enhanced and the possibility of consensus is enabled.

- Methods and techniques must evolve to manage the development or evolution of collective working.

Another central aspect of participative problem solving is the demand that the OR worker is a qualified facilitator. The main mission of the facilitator is to create and support group dynamics in the problem solving process. We talk about group dynamics, when energy and synergetic effects are created in the group work as a result of well-balanced processes where the task is just as important as the group trust and identity. To learn about the art of facilitation, see further Vidal (2004b).

\subsection{Systems thinking}

We have seen in previous sections that systems thinking or the systems approach is a central characteristic of some soft and critical OR approaches as opposed to mechanistic thinking. What is systems thinking? How can systems thinking guide us to systemic intervention? These are questions that are difficult to answer at the moment because there is still a big gap between theory and practice.

Midgley (2000) has taken a first step to give a useful answer to the above-mentioned questions. He has proposed a methodology for systemic intervention that endeavours to:

- Provide a useful systemic language to deal with real life situations;

- Bring together science and ethical reflection in one practice;

- Conceptualise complex situations characterised by interacting issues and multiple, conflicting points of view;

- Reflect about values and boundaries of inclusion, exclusion and marginalisation of actors and issues;

- Sweep into intervention the viewpoints of a wide variety of stakeholders, including those who find themselves marginalised; and

- Choose and/or design an approach that provide the means to engage with others in a flexible and constructive manner, thereby facilitating the development of new social agendas and plans for changes that can command support from those affected by them.

This is an ambitious project, far to be finished. Systemic intervention is a particular form of designing a multimethodological approach. 


\subsection{Creative OR}

The facilitator will use some approaches, methods and techniques to support the problem solving process. These will be selected according to the type of problematic situation on hand, the background and experiences of the clients, and the practical experience of the facilitator. Approaches specify general principles and a step-wise process for problem solving. Rational approaches give advice of how to deal with problems within the boundaries of the system in question. To be rational is to be intelligent problem solver. Hard, soft and critical OR are rational approaches. Creative approaches focus on breaking the boundaries of the system in study. To be creative is to be innovative problem solver.

Creative approaches are what millions of people do to survive every day of their life, yet we get no practice on these skills in our structured, deterministic, safe, and supervised learning environments. Creative problem solving (CPS) deals with situations where boundaries have to be broken, exploring visions for the future of the organisation or community. What characterises the CPS process is that at each stage of this process first we diverge then we converge.

\section{Some of the rules for divergent thinking are:}

- Imaging, reframe and see issues from different perspectives;

- Defer judgement, criticism or negativity kills the divergent process, be open to new experiences;

- Quantity breeds quality, to have good ideas you need lots of ideas;

- Hitchhiking is permitted, in this way a synergetic effect can be achieved;

- Combine and modify ideas, in this way you can create many ideas;

- Think in pictures, to create future scenarios you can even essay to simulate potential solutions;

- Stretch for ideas, imaging ideas beyond normal limits; and

- Do not be afraid to break paradigms, avoid destructive criticism, and add value to the challenged concept.

Some of the rules of convergent thinking are:

- Be systematic, find structure and patterns in the set of produced ideas;

- Develop ways to evaluate ideas, assess qualitative and quantitative measures of ideas;

- Do not be afraid of using intuition, this is the way how most important decisions are taken;

- Avoid quickly ruling out an area of consideration, take your time or better sleep on it;

- Avoid idea-killer views, try the impossible, do not be afraid to clash a wall it is not sure that the wall will always hold;

- Satisfy, do not expend much time in looking for the optimal solution of an illstructured multi-criteria problem;

- Use heuristics, use common sense and experience based rules; and

- Do not avoid but assess risk, it does not mean being blind to risks, for serious consequences be sure to have a contingency plan.

CPS processes always contain phases of divergent and convergent thinking. Divergent thinking produces as many solutions as possible within the available time. The participants will vary in the way they prefer to produce ideas; some will do it by association others by unrelated stimulus. Convergent thinking on the other hand requires from the participants to 
use skills in reality testing, judgement and evaluation to choose the one or two best options from a number of possibilities. It is not unusual that in a group some members will very easily diverge, that is build a list of alternatives, while others will converge very fast by trying to select the best solution from the list and the rest will be passive not knowing what is required of them. Therefore the need of a facilitator, he or she designs a clear and visible process to align the group. Usually the facilitator does not select the participants of the group; very fast he or she has to identify the profiles of the participants.

Problem solving related to strategy development and organisational design demand the use of creative tools within a designed multimethodological approach. These tools will also become part of the OR armoury, see further Vidal (2005).

\section{References}

(1) Ackoff, R.L. (1974). Redesigning the Future. Wiley, New York.

(2) Ackoff, R.L. (1999). Ackoff's Best. Wiley, New York.

(3) Freire, P. (1972). Pedagogy of the Oppressed. Penguin, London.

(4) Habermas, J. (1972). Knowledge and Human Interest. Heineman, London.

(5) Habermas, J. (1974). Theory and Practice. Heineman, London.

(6) Habermas, J. (1976). The analytical theory of science and dialectics. In: The Positivist dispute in German Sociology [edited by Frisby, D.], Heinemann, London.

(7) Keys, P. (ed.) (1995). Understanding the Process of OR. Wiley, Chichester.

(8) Midgley, G. (2000). Systemic Intervention. Kluwer, Plenum, London.

(9) Mingers, J. (1992). Technical, practical and critical OR - Past present and future? In: Critical Management Studies [edited by Alvensson, M. and Willmont, H.], Sage, London.

(10) Mingers, J. \& Gill, A. (eds.) (1997). Multimethodology. Wiley, Chichester.

(11) Nelson, R.R. (1974). Intellectuazing about the Moon-Ghetto Metaphor: A study of the current malaise of rational analysis of social problems. Policy Science, 5, 375-414.

(12) Pidd, M. (1996). Tools for Thinking. Wiley, Chichester.

(13) Rosenhead, J. (1984). Debating Systems Methodology: Conflicting ideas about conflict and ideas. J. Appl. Sys. Ana., 11, 79-84.

(14) Rosenhead, J. (ed.) (1989). Rational Analysis for a Problematic World. Wiley, Chichester.

(15) Taket, A. \& White, L. (2000). Partnership and Participation: Decision-Making in the Multi-Agency Setting. Wiley, Chichester.

(16) Ulrich, W. (1983). Critical Heuristics of Social Planning: A new approach to practical philosophy. Haupt, Berne.

(17) Vidal, R.V.V. (1994). A Sociological Study of OR, PhD thesis in Cultural Sociology. University of Copenhagen (unpublished). 
(18) Vidal, R.V.V. (1995). How to teach/learn OR? Investigação Operacional (Portugal) 15, 97-110.

(19) Vidal, R.V.V. (ed.) (2004a). Applications of Soft OR Methods. Special issue, European Journal of Operational Research, 152(3).

(20) Vidal, R.V.V. (2004b). The Vision Conference: Facilitating creative process. Systemic Practice and Action Research, 17(5), 385-405.

(21) Vidal, R.V.V. (2005). Creativity for Operational Researchers. Investigação Operacional (Portugal), 25, 1-24.

(22) Whyte, W.F. (1991). Participatory Action Research. Sage, Newbury Park. 